\title{
THIS
}
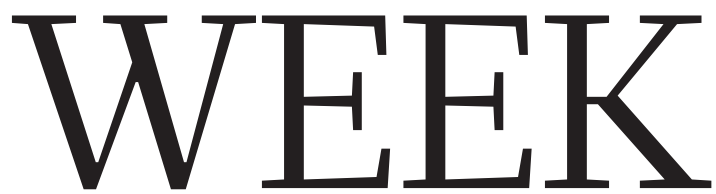

EDITORIALS

FORENSICS Mobile camera converted to colouranalysis kit $\mathbf{p . 6}$
WORLD VIEW How one

institute is tackling gender inequity $\mathbf{p . 7}$
MANE EVENT Lions head

back to Rwanda after 15 years $p .10$

\section{Success in failure}

\section{A failed crop trial of genetically modified wheat still provides crucial lessons for those battling to provide the planet's growing population with a sustainable food supply.}

I $\mathrm{t}$ is rare for failures to be lauded in science. History, as it is often said, is written by the winner. The history of research is no different.

But failure in science is vital. Another cliché about history is equally applicable to scientific flops: people who are ignorant of them are doomed to repeat them. Which brings us to a green - and to some, an unpleasant - field in England.

In 2012, a team based at Rothamsted Research, an agriculturalscience institute a short train ride north of London, planted wheat that they had genetically modified to emit a chemical used by aphids as a warning that they are under attack. The researchers wanted to see whether this would give the crops a way of repelling the damaging pests. They thought that the chemical might also attract insect parasites alerted to the promised presence of aphids.

Before they got the chance, the crops attracted a swarm of protesters. Opponents of genetic modification (GM) technology mounted an imaginative, if sometimes bizarre, campaign against the trial, complete with dubious scientific claims, loaves of bread adorned with cartoon cow heads, and videos promising to 'Take the Flour Back' complete with rock-music soundtrack. The research itself cost $£ 732,000$ (US\$1.2 million) over five years. Securing the site from those who threatened to tear it up cost nearly $£ 1.8$ million.

The idea behind what has, rather unfortunately, become known as 'whiffy wheat' showed promise in the laboratory. Yet in field trials the crop is an unquestionable failure. A paper published on 25 June in the journal Scientific Reports notes that the GM crops "showed no reduction in aphids or increase in parasitism" compared with controls (T. J. A. Bruce et al. Sci. Rep. http://doi.org/5sr; 2015).

This is disappointing on many levels. First, because of the effort - and money - that has gone into the concept. Second, because GM crops will surely have a major role in providing a future sustainable food supply. As Earth's population grows, so does its appetite. Work aimed at increasing crop yields, by both GM and non-GM methods, is among the most crucial research being conducted on the planet. So hostility towards GM research - one reason why it is rare for such crop trials to reach field-scale studies in Europe - is still among the most important societal issues for science to address.

Some opponents of GM crops have reacted with predictable claims: that the trial was a waste of money, that investment in GM science should therefore be cut off, and that this one set-back means the entire concept is flawed. Hardly.

As with most negative results in research, things can still be learnt from this trial. The team might yet modify the way their crop emits the alarm pheromone and may experiment in areas with higher densities of parasites.

The crop failed, but so did the protests. The research was done; a useful result was obtained. Ironically, had the protests succeeded and the trial been abandoned, the protesters would be unable to crow about the crop's failure. GM research continues at Rothamsted, as it does around the world. Some of it will work and some will not.

Those who wish to make an argument against GM crops face major problems. The rise of new techniques such as CRISPR means that what is and is not a GM organism is an increasingly grey area, both scientifically and for regulators.

And these crops, with all the controversy that comes with them, are no longer the sole preserve of huge agri-businesses. The use of GM technology is increasingly being passed to the people who really need it - those in developing countries who are trying to improve the
"Considering all GM crops as a single case is increasingly problematic." agriculture of their nations.

Considering all GM crops as a single case is increasingly problematic. Consumerfriendly traits, such as apples that do not turn brown, now vie with nutritional enhancement for developing nations and drought resistance. Small academic groups around the world are producing locally tailored varieties alongside the engineered staples that major companies sell in huge quantities to farmers in the developed world. And the debate is no longer limited to crops - on page 13, we report on GM pigs that could soon make their way into the human food chain.

All who care about evidence-based policy-making should thank those who continue to struggle against both the difficulties of doing science and the added difficulties caused by people who would see science abandoned. We will all need the fruits - and the cereals - of their labours.

\section{Gene politics}

\section{US lawmakers are asserting their place in the human genetic-modification debate.}

$\mathrm{T}$ The revelation in April that scientists had edited the genome of a human embryo - an inevitable development to anyone paying attention to biotechnological advances - has sparked the biggest bioethical debate of the year and one that will last for decades. The overwhelming consensus is that such embryos should not be brought to term in clinical settings - at least not for now. The debate over when, if ever, that should take place has played out in the scientific literature in duelling articles, arguments about the technology's efficacy and calls for an Asilomar-like conference on bioethics.

So it is little surprise that lawmakers are weighing in. On 16 June, a subcommittee of the US House Committee on Space, Science and 
Technology held a hearing on human gene editing with witnesses who included Jennifer Doudna, a biochemist at the University of California, Berkeley, who was one of the inventors of the genome-editing system CRISPR, and the Institute of Medicine (IOM) president Victor Dzau.

The climate was more educational than controversial, with lawmakers asking the usual questions about the risks, benefits and ethics of engineering future generations of the human race. Parallels were drawn with another ongoing debate over 'three-parent embryos', in which an egg cell's diseased mitochondria are replaced with healthy mitochondria from a second woman. A decision on whether to allow that procedure in the United States is in the hands of the US Food and Drug Administration (FDA), which has commissioned an IOM report on the topic that is due this winter.

While the research and technology subcommittee grilled the experts, a separate subcommittee - of the House Appropriations Committee that funds the FDA - was meeting elsewhere on Capitol Hill to draft the agency's 2016 budget. The subcommittee wants to take no chances with human modification: a bill that it released on 17 June bans the FDA from using public funds to evaluate applications for clinical trials involving genetically modified human embryos. Ironically, the current wording could backfire: applications for permission to investigate new drugs are automatically approved in 30 days unless the FDA blocks them, which would require funds.

If the budget passes, this clause would be the first time that lawmakers have used the FDA to limit human embryo research. A 1996 law known as the Dickey-Wicker Amendment bans the use of federal funds to create human embryos for research, but does not pertain to FDA regulation. The National Institutes of Health (NIH) reaffirmed in April that heritable genetic modification falls under the Dickey-Wicker rule, and director Francis Collins said that clinical application of such technology is "viewed almost universally as a line that should not be crossed".

Nevertheless, Congress is determined to have a say. Deeply embedded in a report accompanying the appropriations bill are orders from the funding committee that the FDA appoints "an independent panel of experts, including those from faith-based institutions with expertise on bioethics and faith-based medical associations" to evaluate

the IOM three-parent embryo report when it is released and to report back.

Although the FDA budget is far from becoming law - after undergoing another round of editing, it must still be passed by Congress and the Senate and signed by the president - the implication is clear. The powerful spending committee that holds the purse strings wants to be involved in the debate: an understandable and indeed necessary posi-

"This clause would be the first time that lawmakers have used the FDA to limit human embryo research." organizations' interpretation of Dickey-Wicker and briefly shut down all NIH-funded human embryonic stem-cell research.

As this journal has said, all voices, including those of faith-based groups, should be heard in the debate over human-genome editing; indeed, the input of highly influential religious groups is essential to make a decision on how and if to regulate, especially in the United States. But the IOM committee already includes a professor of religious studies - so why duplicate the effort? This mandate to the FDA is not one that should come from a secular government, which seems to be seeking to impress conservative supporters. As one ethicist put it: "It is a sign that the culture wars aren't dead."

When it comes to human-genome editing, however, those wars are a reality that all must face - and that is a good thing. This opening salvo from Congress shows just how complex the coming debate over human genomic modification will be. Academics have spent the past months debating among themselves how to proceed with research and clinical applications, sometimes acting as though they will be the arbiters of the final decision. As public awareness of the technology increases, that ethical discussion will rightly be taken out of their hands alone and planted firmly in those of broader society.

\section{Light detective}

\section{Smartphone camera set to come to the aid of sleuths, scientists and wine lovers.}

\footnotetext{
A s any reader of detective fiction knows, a crucial clue needed to solve a murder is the time of death. The hero detective, typically, is frustrated by the vague responses of the forensics team: "sometime between Tuesday night and Thursday morning" does little to narrow down the range of suspects. Scientists have long tried to help. And forensic science, with DNA analysis at the forefront, now ensures that more real-life criminals can expect a knock on the door, sometimes decades after they thought they had evaded detection. However, it remains effectively impossible to accurately judge the age of a bloodstain. Corpse excluded, bloodstains are typically the most common piece of evidence encountered at a homicidal-crime scene.

Colour could be the key. After blood leaves the body it starts to dry; as it does so, it changes from red to brown. Back in 1907, the Italian researcher Louis Tomellini produced a chart of 12 bloody spots, to illustrate this colour change over a year. As forensic science developed through the twentieth century, so did bloodstain analysis. By the 1960s, researchers were using photospectrometry, recording reflectance spectra and working out how the rate of Tomellini's colour changes could be affected by different atmospheric conditions. These are useful
}

observations, and forensic analysis of the colour of bloodstains is today a common part of the forensics team's work. But the results are still too variable for the analysis to stand up in court.

Colour provides more-useful data than many might think. Spectrometry is a valuable technique in many areas, from drug discovery to environmental monitoring. And astronomers use spectrometers to probe the atmospheres of distant exoplanets for conditions that might support life. Spectrometers, in other words, have become indispensable instruments. But they tend to be expensive, complex machines. The most precise can also be bulky, making them difficult to use in the field. On page 67 of this issue, scientists describe a possible step forward. They have built an optical spectrometer that is both small and powerful, and potentially cheap enough to find use in consumer electronics - to detect corked wine perhaps.

Like many modern images, those analysed by the scientists are taken with a smartphone camera. These are selfies from the quantum world: the camera is converted into a spectroscope using suspensions of particles called colloidal quantum dots. Exposed to light, these tiny particles produce vivid colours, with the shade and hue determined by the particle size. With the right mixture of particles, a coating can be applied that can filter and analyse the wavelengths (and so colour) of incoming light.

The research is discussed in a News \& Views article on page 39, which describes how it could be used to produce $\rightarrow$ NATURE.COM To comment online, click on Editorials at: go.nature.com/xhunqv "ubiquitous sensing elements in household devices connected to the Internet". Beware would-be bloody criminals, your fridge is watching you. - 